\title{
Insights for Farmer Training Programs from System Dynamics: A Case Study from Northern Michigan
}

\author{
L. S. Olabisi ${ }^{1}$, O. Elegbede ${ }^{2}$, M. R. Raven ${ }^{3}$
}

\begin{abstract}
Training programs for new farmers have been proposed as a solution to rural food insecurity, rural development, and the recruitment and training of younger farmers simultaneously. However, evaluation of these programs and evidence for their individual or collective impact is sparse. In this paper, we use in-depth interviews combined with a system dynamics model to evaluate the current and potential effectiveness of a farmer training program in Michigan's Upper Peninsula. We use the model to represent the theoretical progression of farmers through three subsequent stages of skill acquisition: training, new farmer (practicing skills on land owned by the program) and experienced (farming on their own). We find that recruitment, access to local markets, rapidity of skill acquisition, and access to start-up costs are all important factors that facilitate trainees' transition to farming on their own, but of these, start-up costs for independent farming appear to be the most significant barrier. While this model is exploratory and not predictive, these insights can inform the design of effective programs for training farmers who will ultimately go on to start their own operations. In addition, this study also demonstrates how systems dynamics can be a valuable method to evaluate and maximize the effectiveness of training programs.
\end{abstract}

\section{Keywords}

Training, Systems modeling, evaluation, rural livelihoods, adoption

1. Laura Schmitt Olabisi, Associate Professor, Michigan State University 480 Wilson Road, Room 138, East Lansing, MI 48824

schmi420@msu.edu, https://orcid.org/0000-0002-6557-9469

2. Obafemi Elegbede, Research Associate, Michigan State University elegbede@msu.edu, https://orcid.org/0000-0002-5935-0991

3. Matt R. Raven, Professor, Michigan State University 480 Wilson Road, Room 310A, East Lansing, MI 48824 mraven@msu.edu, https://orcid.org/0000-0002-8271-2321 


\section{Introduction and Problem Statement}

Food insecurity and a lack of affordable, nutritious foods are persistent problems in the rural United States (Denney et al., 2017; Ramirez et al., 2017). The farming population in the United States is aging, with one quarter of farm operators being 65 or older, compared with only $8 \%$ of the general population (United States. Congress. Senate. Special Committee on, 2008). Training programs for new farmers have been proposed as a solution to rural food insecurity, rural development, and the recruitment and training of younger farmers simultaneously. However, evaluation of these programs and evidence for their individual or collective impact is sparse.

The Upper Peninsula of Michigan is a rural region that exemplifies the linked challenges of economic insecurity, an aging farmer population, and a supply for locally produced fruits and vegetables that does not meet consumer demand. According to a 2011 survey conducted by Michigan State University Extension (MSUE) on a sample of 108 Upper Peninsula (U.P.) farmers, only $8 \%$ of the respondents derive all of their income from their farms. For most, the farm generated up to $10 \%$ of the household income. Nearly three-quarters (70\%) were over the age of 51 and three-quarters (75\%) indicated they did not have someone to take over for them when they stop farming. Nearly half of the respondents (48\%) indicated they wanted to expand their operations. Many producers indicated they needed additional help and technical support. The report pointed out that as interest in local food continues to increase so will the pressures on U.P. producers to keep pace with the demand. Furthermore, the report concluded that a vibrant local food economy was integral to the health of small rural communities (Lantz \& Walk, 2011).

As a solution to these documented challenges, Michigan State University's Upper Peninsula Research and Extension Center has developed formal and non-formal research-based educational programs targeting beginning farmers and avocational growers to increase the number of farmers in the U.P. growing nutrient dense food, thereby proposing to fill the gap between supply and demand for healthy local foods. The program provides access to organically managed land, equipment and hand tools, and shared infrastructure (hoop houses, transplant greenhouses, germination chamber, a tractor, etc.). In addition, the program provides subsidized on-site housing, access to markets, training in National Organic Program and USDA Good Agricultural Practices record keeping, guidance with farm business plans, and networking opportunities with other farmers and educational workshops. If successful, the farmer training program could be a model for other such programs in the United States seeking to improve healthy local food access by equipping aspiring farmers.

Despite the potential benefits of the farmer training program, the enrollment and graduation rates have been low. In the four years since the program was established, six farmers have participated in the program, while the original target completion number was between 12 and 24. We conducted a qualitative evaluation of the program, combined with an exploratory system dynamics model, to understand the barriers and opportunities involved in recruiting farmers to the program, supporting them in completing the program and in their transition to 
independent farming, and assessing the potential extent of the impact on agriculture in the U.P. In this work, we seek to capture the complex interactions and dynamic feedbacks between the educational program for beginning farmers, challenges to technology implementation, and economic barriers to entry into farming. Consequently, we are using system dynamics modeling to represent these dynamics (Meadows, 2008).

System dynamics modeling was developed in the 1960s and has been used in a wide variety of fields to investigate how complex systems behave over time (Forrester, 1968). It is a quantitative modeling technique based on a series of differential equations, but it is also capable of representing qualitative information gleaned from interviews and focus groups through causal logic (Scott et al., 2013). System dynamics has been proposed as a useful tool for conducting program evaluation, because it can demonstrate potential impacts of a program into the future, and of outlining the effects of programmatic changes (Merrill et al., 2013). It has also been commonly used to represent technology adoption (Amelia et al., 2014; Fisher et al., 2000). We drew on the technology adoption models for this study, because we are representing a group of farmers acquiring and then using a set of technologies for growing nutrient dense produce in the U.P. As represented in the model, potential farmers learn about the program from educational workshops offered by the North Farm at the Upper Peninsula Research and Extension Center. The farmers trained in a suite of technologies demonstrated in the program, including walk behind tractors, seeders, hoes, price planning and assessments, etc. Then the farmers decide whether to implement these technologies or not. The process of recruiting new trainees is driven by information exchange between potential farmers and those who have gone through the program, as posited by diffusion theory (Rogers, 2003).

Famers that graduate from the program are assumed to be more skilled at growing nutrient dense produce using appropriate technology, and more skilled at developing a business plan that will help with their future farms. We used a system dynamics model to model these patterns of adoption and the ways in which the technologies could diffuse through the farming population of the Upper Peninsula. The research question we sought to answer with this model: what programmatic interventions would be most effective in increasing the recruitment, graduation, and establishment of beginning farmers relative to the training program?

\section{Methods}

We conducted semi-structured scoping interviews with beginner farmers to understand their current farming operations, goals, technology and methods learned from the program, profitability, productivity, challenges and constraints they face and benefits from the program. We carried out the study at the North Farm in Chatham, located in the Upper Peninsula of Michigan, and at Michigan State University, East Lansing Michigan. The study sample consisted of six farmers that were in the program for at least a year. The farmers in program range in experience from beginners to experienced farmers. We used a survey that had both structured and semi-structured questions, as well as an exploratory approach in the survey to get more 
information that might not have been revealed in the structured questions (Glesne, 2010). Some of the data was collected face-to-face and the rest was collected over the phone. In addition, we used data generated from the MSU Upper Peninsula Research and Extension Center: North Farm Apprentice Farmer Program Evaluation Summary report that was conducted in December 2018. The survey along with the report contributed to a deeper understanding of the issues related to the program.

We used information from the scoping interviews and the 2018 evaluation report from the North farm to create and parameterize the system dynamics model, using Vensim ${ }^{\circledR}$ software. The logical framework follows Rogers' diffusion of innovation model (Rogers, 2003) (Figure 1).

\section{Figure 1}

Structure of System Dynamics Model

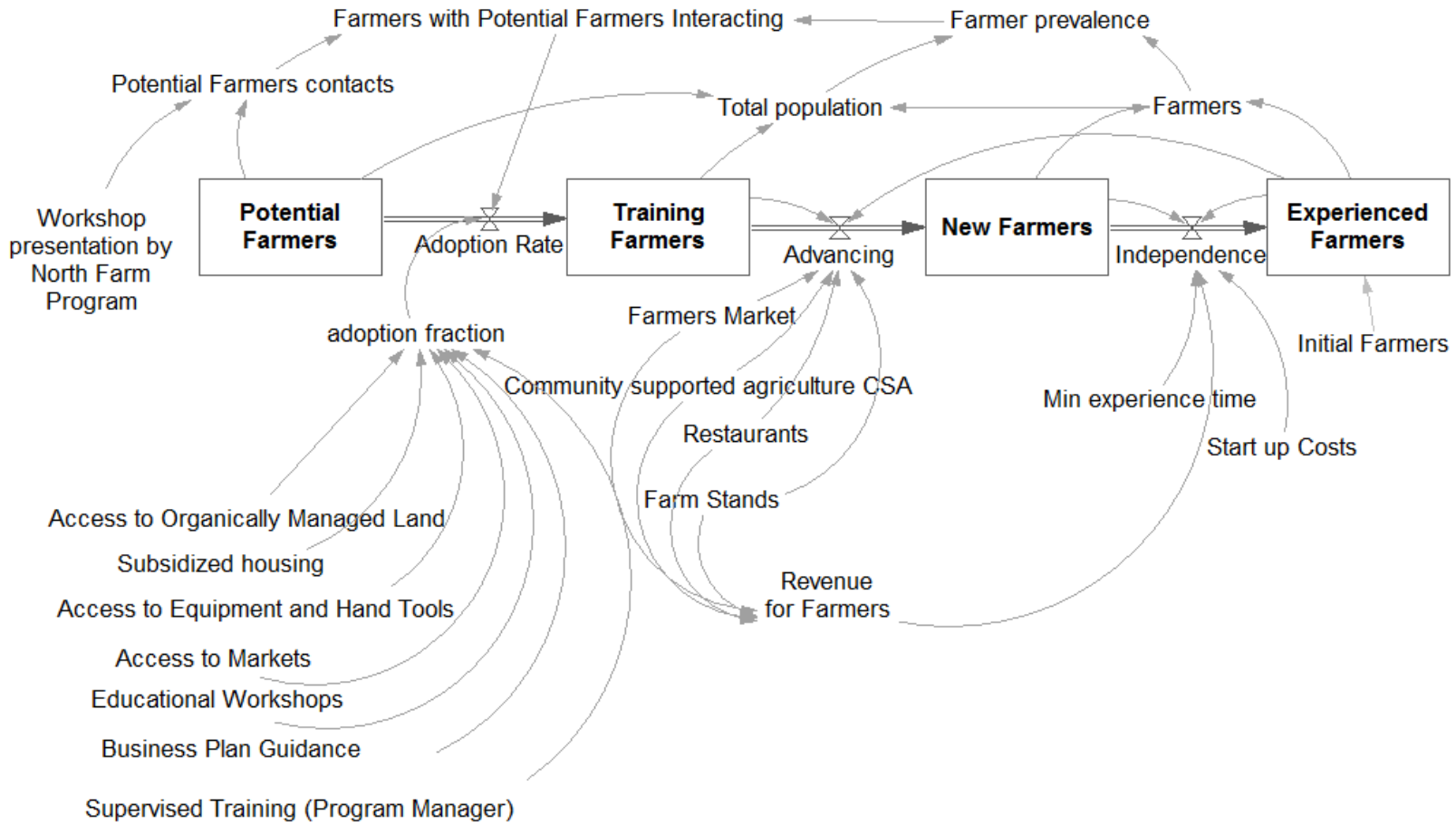

Note. Model structure depicting the progression of farmers through training, to establishment of a 'new' farm on land provided by the training program, to experienced farmer status on their own land.

Potential farmers (farmers who join the training program) advance through three stages of skill acquisition: training, new farmer (practicing skills on land owned by the North Farm) and experienced (farming on their own). Their ability to advance through these stages is both mediated and facilitated by factors discovered through the interviews. Once the structural logic of the model was established, values for the parameters were derived from the interviews and the North Farm evaluation report. For example, we asked interviewees how many months they estimated for the transition from 'new farmer' to 'experienced farmer' (successfully farming on 
their own upon completion of the North Farm program), and the average response was 40 months.

\section{Findings}

\section{Interviews}

The skills acquired through the North Farm program allowed beginner farmers to learn how to start a business and transition to the 'training farmers' category. As described by the interviewees, these skills included networking, creating invoices for customers, and developing avenues to sell their products at local restaurants and through community-supported agriculture, in partnership with the North Farm. Trainees also learned about viable farm business models, including price planning, price assessment, calculations of labor, and soft skills, as well as soil management and safe produce handling. In addition, the farmers were provided with technology for sustainable production practices, such as harvesting tools, water wheel planters, rotor tillers, walk-behind tractors, drip irrigation systems, and hand cultivators. All of these factors were added into the system dynamics model as variables conditioning the transition rate of farmers between 'training', 'new', and 'experienced' categories.

\section{Model}

The baseline behavior of the system dynamics model depicting adoption of the North Farm technologies by the training population followed a typical S-curve growth pattern over the 30 years of the model run (Figure 2).

By the end of the model run, thirteen total farmers had successfully transitioned to farming on their own land, representing the cumulative impact of the North Farm program. The number of farmers in the 'training farmer' category grew as they were trained at the North Farm, then declined as these farmers successfully transitioned to farming on their own land. In the baseline model run, we assumed that all farmers entering the program had access to materials they needed for training: access to organically managed land, subsidized housing, access to equipment and hand tools, access to markets, educational workshops, business plan guidance, and supervised training under the guidance of a program manager. This baseline run mirrors the setup of the North Farm Apprentice Farmer Program, which provides this support to enrolled farmers. 


\section{Figure 2}

System Dynamics Model Output
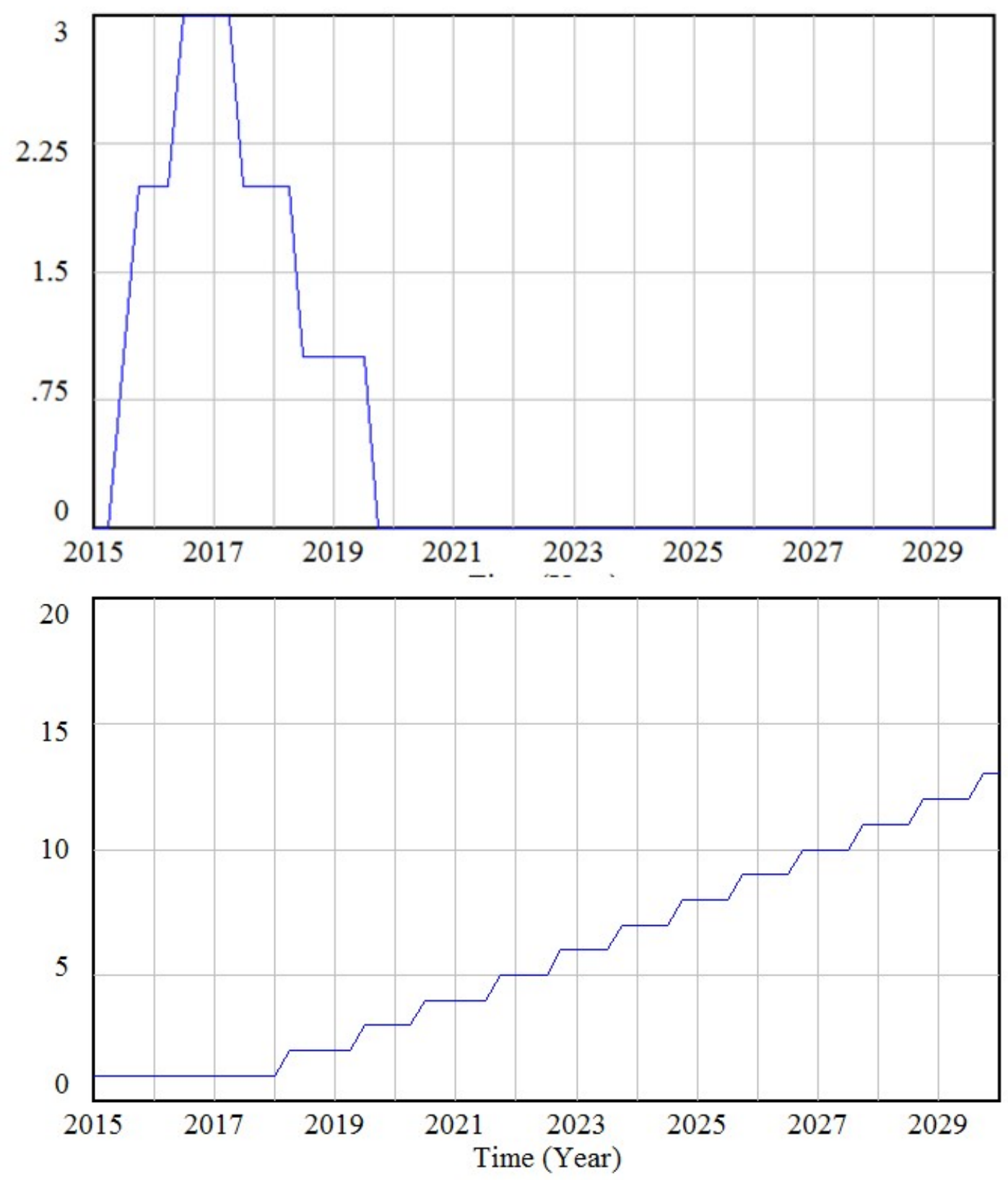

Note. System dynamics model results depicting number of farmers in the 'training farmers' category (top) and the 'experienced farmers' category (farmers who have successfully transitioned to farming on their own land, bottom) over the 15-year model run under baseline conditions.

The flow of farmers into the program is ultimately limited by the amount of contact and positive word of mouth generated by the trainees enrolled in the program. In the context of the North Farm model, this was represented by the number of workshops held, driving interest from potential farmers in enrolling in the program. When the number of workshops was increased from one per quarter to one per month, this had the effect of sending a greater 
'pulse' of farmers through the system initially. Without additional support for farmers to transition into successfully starting their own operations, however, this did not result in substantially greater numbers of farmers becoming independent (Figure 3).

\section{Figure 3}

Model Output: Results of Program Interventions
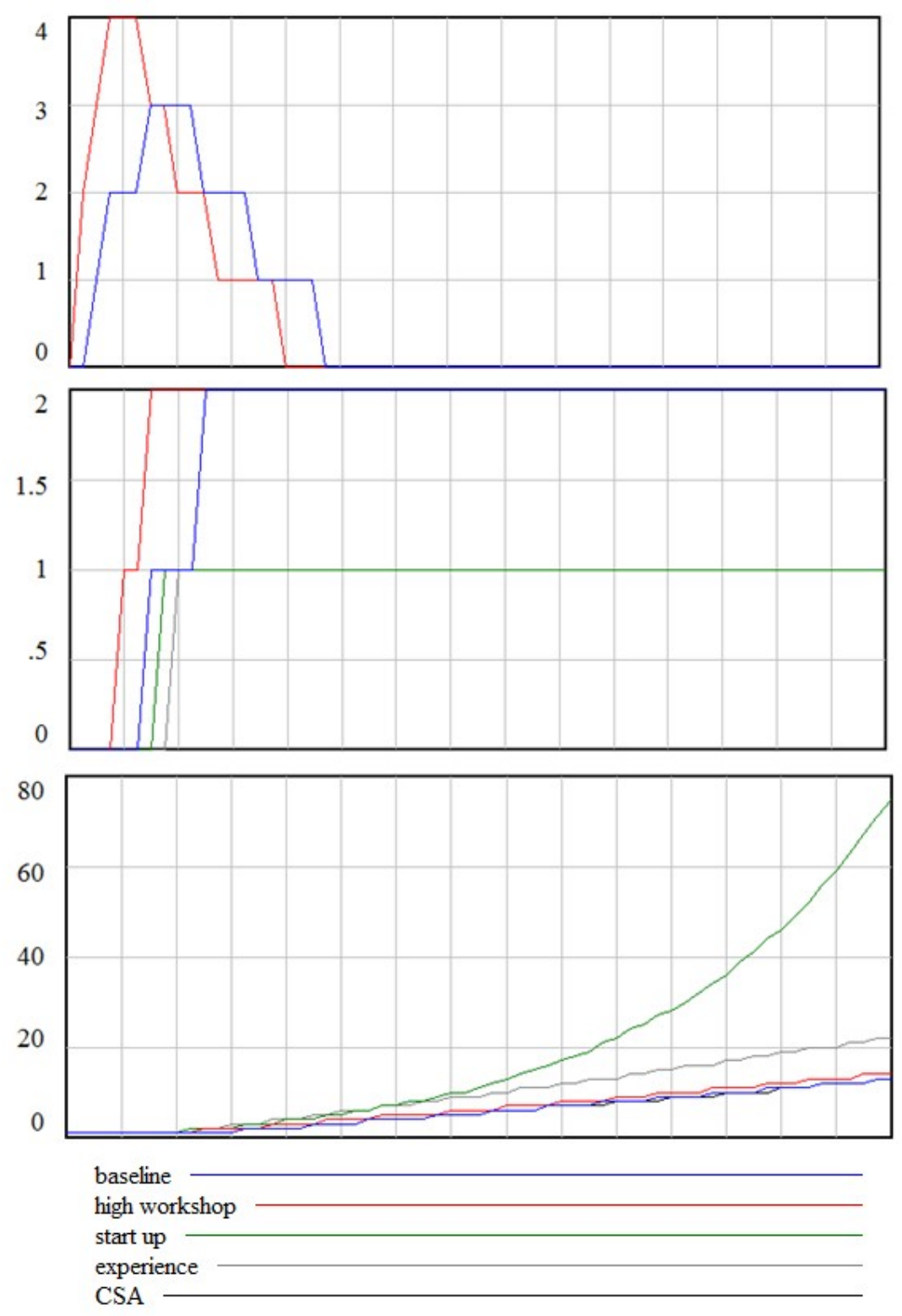

Note. System dynamics model results depicting number of farmers in the 'training farmers' category (top), number of farmers in the 'new farmers' category (farming on land provided by the training program, middle) and the 'experienced farmers' category (farmers who have successfully transitioned to farming on their own land, bottom) over the 15-year model run under four scenarios: 'high workshop' (farmers are recruited to the training program through monthly rather than quarterly workshops); 'start up' (startup costs for farmers starting their own operations are subsidized); 'experience' (time for farmers starting their own operations to gain the necessary experience is reduced from 3.5 years to 1 year) and 'more CSA' (a 2x increase in the number of CSA customers). 
Another scenario involved decreasing start-up costs for farmers to start their own farm operations after training in the program. This scenario had the greatest impact on the number of experienced farmers by the end of the model run (increasing this number to 75), but had minimal impact on the number of farmers in the training program or the number of new farmers (Figure 3). Decreasing the amount of time needed for farmers to gain the experience to start their own operation from 3.5 years to 1 year also increased the number of experienced farmers by the end of the model run above the baseline, but did not have as great an impact on increasing this number as did a decrease in start-up costs.

Finally, increasing direct sales of vegetables through community-supported agriculture (i.e. doubling the enrollment in CSAs from $25 \%$ of the population to $50 \%$ ) did not have a substantial impact on number of farmers progressing through the system (Figure 3 ). This is because, in the absence of trainees being recruited into the program, there are not enough farmers to take advantage of increased CSA sales. CSA sales are also split between the new farmers and the experienced farmers, and new farmers are better able to take advantage of them because of the land and resources they can access through the North Farm program. This is a cautionary insight for the design of such programs, which should take care not to place their trainees and their graduates in competition for limited market share. This may be more important for programs that are large in scope relative to their local markets.

When all interventions to boost the number of experienced farmers were combined into one model run (increasing workshops, decreasing startup costs and experience needed to start one's own operation, and increasing CSAs), the number of experienced farmers after 30 years reached 203. This is a substantial impact for one training program at one location and could potentially transform the food landscape in the Upper Peninsula region, especially if duplicated at other sites (Figure 4). 


\section{Figure 4}

Model Output: Number of Experienced Farmers

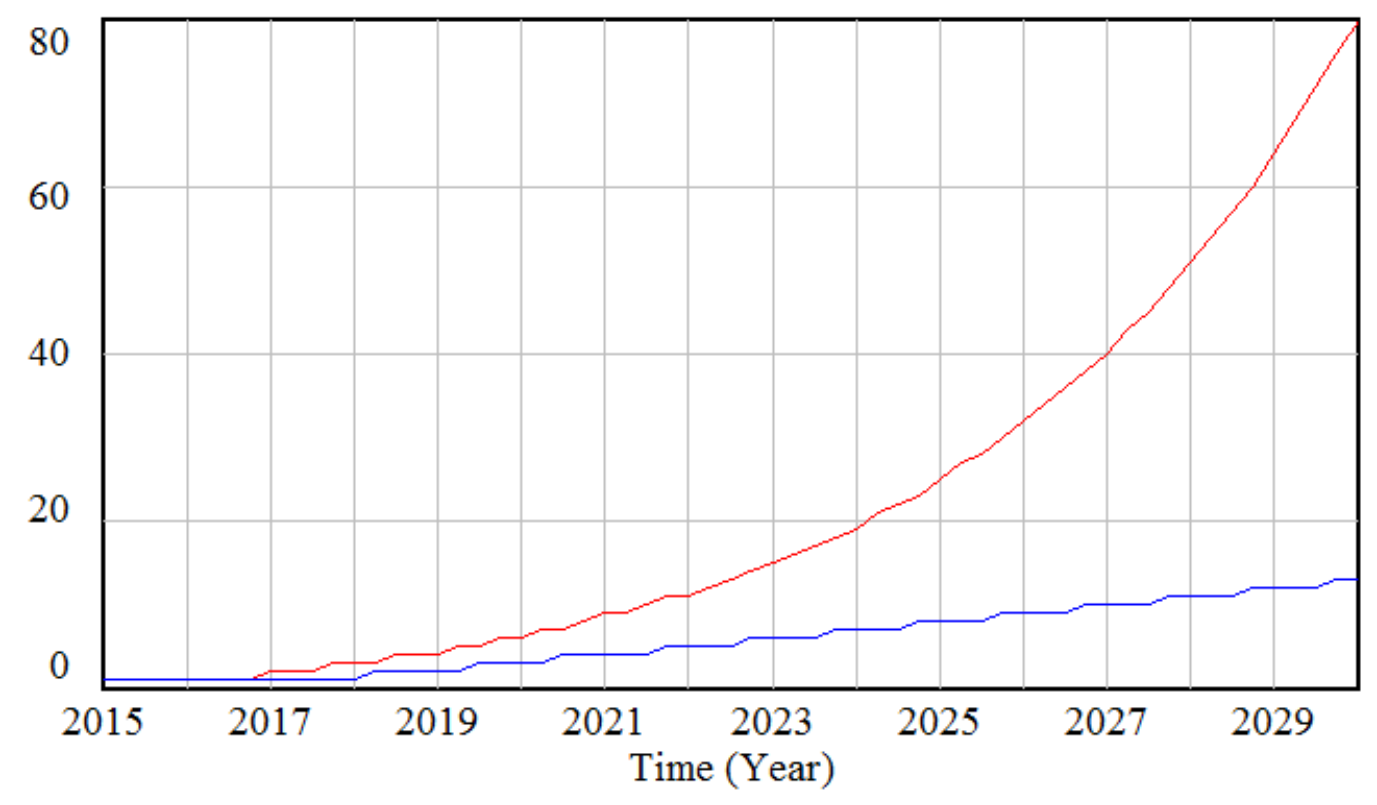

experienced farmers integer : baseline

experienced farmers integer : all interventions

Note. System dynamics model results depicting number of farmers in the experienced farmer category under baseline conditions, and with all interventions to increase number of farmer recruited and trained (more workshop recruitment, reduced startup costs, increased CSA customers, and reduced time to gain experience).

This is an exploratory model, based on an in-depth qualitative study of one farmer training program, and is useful for gaining general systemic insights rather than crafting detailed predictions. For example, without a larger survey of farmer training programs across the country with different training models, it is difficult to place weights indicating relative importance on the different components of the program that allow for successful training (e.g., access to tools, subsidized housing, supervised training, etc.). In our model, we assumed the same weight for all of these elements, even though interviewees highlighted the supervisory guidance of a program manager as being particularly important to their learning process, which would imply that the selection of the person to lead the training program is particularly important for its success. Similarly, we were not able to generate detailed market scenarios to guide where new farmers might gain the best advantage in selling their products (e.g. to restaurants, CSAs, or farmers' markets). A detailed economic analysis of produce markets in Michigan's Upper Peninsula would be necessary to provide this type of guidance.

Nevertheless, the model provided substantive insights into the design of successful farmer training programs, and we were able to use it to test commonly proposed interventions for increasing the flow of new farmers into the farming population. We found that decreasing start-up costs for farmers striking out on their own (e.g. through loans, subsidized land purchase and/or leasing arrangements) would be particularly effective in transitioning farmers 
from a training period to establishing their operations. At the same time, increased recruitment of farmers into a training program will not ultimately result in more local farmers unless their transition into farming on their own is also facilitated, for example through reduced or subsidized start-up costs, as described above.

\section{Conclusions, Discussion, and Recommendations}

Using a system dynamics model, we were able to depict the training of new farmers producing vegetables for local markets in the Upper Peninsula of Michigan as a pipeline, with barriers to entry and opportunities for intervention. The model represents each stage of progression from farmers in training, to new farmers operating on land provided by the training program, to experienced farmers running their own operations. We built the model using in-depth interviews with farmers in the North Farm Apprentice Farmer Program, combined with a system dynamics framework depicting adoption of new technologies. While this model is exploratory and not predictive, we were able to glean insights around the design of effective programs for training farmers who will ultimately go on to start their own operations. To increase the number of experienced farmers, more programs will be needed to ease the startup costs for farmers starting their own operations. Recruiting more farmers into a training program will not result in more farmers that are independent unless this startup 'bottleneck' is addressed. Programs should be careful not to engender competition for customers between farmers in training and farmers who have graduated the program to start their own operations. While modest in size, training operations like the North Farm Apprentice Farmer Program could have a substantive impact on recruiting and establishing new farmers over time. Finally, this study also demonstrates how systems dynamics can be a valuable method to evaluate and maximize the effectiveness of training programs.

\section{References}

Amelia, D. F., Kopainsky, B., \& Nyanga, P. H. (2014). Exploratory model of conservation agriculture adoption and diffusion in Zambia: A dynamic perspective. Paper presented at the 32nd International Conference of the System Dynamics Society, Delft, Netherlands.

Denney, J. T., Kimbro, R. T., Heck, K., \& Cubbin, C. (2017). Social Cohesion and Food Insecurity: Insights from the Geographic Research on Wellbeing (GROW) Study. Matern Child Health J, 21(2), 343-350. https://doi.org/10.1007/s10995-016-2119-5

Fisher, D. K., Norvell, J., Sonka, S., \& Nelson, M. J. (2000). Understanding technology adoption through system dynamics modeling: implications for agribusiness management. The International Food and Agribusiness Management Review, 3(3), 281-296. https://doi.org/10.1016/S1096-7508(01)00048-9

Forrester, J. W. (1968). Principles of Systems. Pegasus Communications. 
Lantz, N., \& Walk, M. (2011). Upper Peninsula agriculture assessment. Retrieved from East Lansing MI:

Meadows, D. (2008). Thinking in Systems: A Primer. Chelsea Green.

Merrill, J. A., Deegan, M., Wilson, R. V., Kaushal, R., \& Fredericks, K. (2013). A system dynamics evaluation model: implementation of health information exchange for public health reporting. Journal of the American Medical Informatics Association : JAMIA, 20(e1), e131-e138. https://doi.org/10.1136/amiajnl-2012-001289

Ramirez, A. S., Diaz Rios, L. K., Valdez, Z., Estrada, E., \& Ruiz, A. (2017). Bringing Produce to the People: Implementing a Social Marketing Food Access Intervention in Rural Food Deserts. J Nutr Educ Behav, 49(2), 166-174 e161.

https://doi.org/10.1016/j.jneb.2016.10.017

Rogers, E. (2003). The Diffusion of Innovations. The Free Press.

Scott, R. J., Cavana, R. Y., \& Cameron, D. (2013, July 21-25, 2013). Evaluating long-term impact of qualitative system dynamics workshops on participant mental models. Paper presented at the 31st International Conference of the System Dynamics Society, Cambridge, MA.

United States. Congress. Senate. Special Committee on, A. (2008). Harvest over the horizon [electronic resource]: the challenges of aging in agriculture : hearing before the Special Committee on Aging, United States Senate, One Hundred Tenth Congress, first session, Washington, DC, June 21, 2007.

(C) 2020 by authors. This article is an open access article distributed under the terms and conditions of the Creative Commons Attribution license (http://creativecommons.org/licenses/by/4.0/). 